\title{
Behavior of Chemically Dispersed Oil in Marine Sediment
}

Jian Hua

Associate Professor, Department of Marine Engineering, National Taiwan Ocean University, 2 Pei-Ning Rd. Keelung, Taiwan 20224, R.O.C

Follow this and additional works at: https://jmstt.ntou.edu.tw/journal

Part of the Engineering Commons

\section{Recommended Citation}

Hua, Jian (2009) "Behavior of Chemically Dispersed Oil in Marine Sediment," Journal of Marine Science and Technology. Vol. 7: Iss. 1, Article 5.

DOI: $10.51400 / 2709-6998.2510$

Available at: https://jmstt.ntou.edu.tw/journal/vol7/iss1/5

This Research Article is brought to you for free and open access by Journal of Marine Science and Technology. It has been accepted for inclusion in Journal of Marine Science and Technology by an authorized editor of Journal of Marine Science and Technology. 


\section{BEHAVIOR OF CHEMICALLY DISPERSED OIL IN MARINE SEDIMENT}

\begin{abstract}
Keywords: Dispersant, Dispersed oil, Marine sediment, Adsorption characteristic, Oil spill.

ABSTRACT

This laboratory study was to describe properties of four chemically dispersed oils within natural beach sands. The influence of temperature on the adsorption characteristics of dispersed oil to marine sediment was almost negligible, within 10 to $30^{\circ} \mathrm{C}$. With certain amount of oil and varied dispersant/oil ratio, oil in top sediments following flushing was not affected by the increase in dispersant application. The application dosage of dispersant had no more influence on releasing oil to deeper sediment or water than the amount of oil applied. When the outflow rate of flushing water doubled, the amounts of oil retained in surface sediment following flushing increased for about $6 \%$. It was observed that the tested soap water acted effectively in dispersing floating oil, which was similar to that of the chemical dispersant used in this study.
\end{abstract}

Jian Hua*

\section{INTRODUCTION}

The extensive shipping of crude oil and petroleum products over the world's oceans has increased concern about the effects of the accidental spillage of petroleum in the marine environment. Since the early days of contingency planning for marine oil pollution, chemical dispersants had been widely used to combat oil spills at sea. However, the use of dispersants during Torrey Canyon oil spill in 1967 was followed by long-term disturbances of the ecosystems of the dispersant-treated areas. This led to a restrictive use of such chemicals in many countries for decades (Harris and Wells, 1979). On the other hand, due to the important role of dispersant in oil spill contingency planning in most countries, there has been continuous research into the use, limitations, and application techniques of dispersants.

Dispersants were commonly used to enhancing the formation of smaller oil droplets owing to the surface

Paper Received Nov. 10, 1998. Revised June 11, 1999. Accepted June 30, 1999. Author for Correspondence: Jian Hua.

*Associate Professor, Department of Marine Engineering, National Taiwan Ocean University, 2 Pei-Ning Rd. Keelung, Taiwan 20224, R.O.C.. active substance. Dispersant drops fall on the oil slick and interact with it in some complex, only partially understood manner. The dispersant is usually denser than the oil (and occasionlly denser than seawater), and thus the drop tends to sink into the oil, possibly dissolving and mixing. Volatile hydrocarbons partition into available air spaces and into exposed organisms, were subject to microbial degradation. Factors that exerted a lesser influence (under the given conditions) were wind speed and temperature (Anderson et al., 1989).

Some estimates and measurements of these profiles have been made. Canevari and Lindblom (1996) stated that concentrations of 1 to $10 \mathrm{mg} / \mathrm{L}$ of dispersant occur only for a short time during chemical dispersion of an oil spill at sea. Griffiths et al. (1991) speculated that concentrations of 1 to $12 \mathrm{mg} / \mathrm{L}$ Corexit 9527 could be achieved in shallow inshore areas where tidal and wind energies are often low. While evaluating dispersants at sea is desirable, the routine use of at-sea testing for research purposes could be prohibitively expensive. The development and selection of a laboratory test that had real significance and meaning in terms of performance at sea was therefore a subject of great importance (Mackay et al., 1984).

Currently manufactured dispersants have mainly been developed for use in oceanic environments, i.e. with salinities of about $30 \%$, and are known to have poorer performances at lower salinities. Low water temperature is another factor adversely affecting the effectiveness of dispersants. The relative effect of temperature on oil and dispersant has been widely discussed and conclusions have always been made that dispersants are less effective at lower temperatures. However, Cox (1981) and Schultz (1981) as well as Zitko and Carson (1969) have obtained contradictory results with increased effectiveness as a result of decreased dispersant temperature. Since the characteristics of the tested dispersants in these studies were not known, it was not possible to illuminate the reasons behind the contradictory results. It was plausible, however, that the solvent base of the dispersant is the reason, i.e. dispersants of water-miscible and -immis- 
cible behave differently, specifically at low temperature.

There was relatively little understanding about the sorption of oil hydrocarbons to particles such as detritus, sediments, and organisms in the water environment. It was clear, from studies, by Anderson et al. (1989) on polycyclic aromatic hydrocarbons of particles and in zooplankton feces in oiled areas that many routes were available for transport of hydrocarbons to these sediments. Many studies have shown that oil stranded within littoral and sublittoral sediments at spill sites often changes little in character and was very persistent (Harris and Wells, 1979; Blumer and Sass, 1982; Blumer et al., 1983; Rashid, 1974; Vandermeulen, 1975).

The testing of the fate and effects of dispersed oil in seawater has received considerable emphasis in recent years. However, very few studies have been designed to determine the fate and the effect of dispersed oil in sediments and the factors controlling the interactions of dispersed oil droplets with marine sediments and the potential effects on benthic biota. Rowland et al. (1991) used Nigerian crude oil 1100 WD dispersant, and intertidal sediments near Milford Have, U.K. to conduct both field and laboratory studies. Sediment columns used in the laboratory were obtained from the field. Based upon the results obtained by Karickhoff et al. (1989), the fate of hydrophobic organic pollutants (with water solubility of less than a few parts per million) in a natural water system was highly dependent upon their sorptive behavior. In addition to affecting the physical movement of pollutants, sorption could be involved directly in pollutant degradation via surfaceassociated chemical processes. Moreover, natural sediments could indirectly mediate solution-phase processes by altering the pollutant concentration in solution or by providing a buffered solution-phase ion suite that may affect the dielectric properties and acidity of the solution phase.

Existing data pointed to a large number of different sorbent properties as keys to sorption in given situations (Pionke and Chesters, 1973; Bailey and White, 1970). The high degree of variability and complexity in sediment composition and potential sorptive interactions seemed to preclude the possibility of developing a simple, systematic procedure for predicting sorption parameters. Reasonable estimation of the sorption be- havior of hydrophobic pollutants could be made from a knowledge of the particle size distribution and associated organic carbon contents of the sediment and the octanol/water distribution coefficients of the pollutant (Kairckhoff et al.,1989).

Although dispersants were being widely used in many areas, it was believed that the use of dispersants on shore line might be of questionable value and should not be recommended. However, their use, in comparatively shallow coastal water, might move more oil into marine sediments than would be the case with oil left to disperse naturally, or it might make the oil more mobile causing it to move offshore and be diluted in deeper water.

The objective of this laboratory study was to describe some of the properties of some chemically dispersed oils within a natural beach sands. Experiments were conducted to determine:

1. The difference in mobility and adhesion at the top of beach sands, among various chemically dispersed oil.

2. The effect of various water flushing rates on the mobility of sand-bond oil treated with chemical dispersant.

3 . The effect of various water flushing times and temperature on the movement of dispersed oil through sands.

4. The effect of various water flushing times on the mobility of dispersed oil through sand, when soap water was used as an alternative to chemical dispersant.

\section{METHODS AND PROCEDURE}

\section{Selection of oils and dispersants}

The oils used include Arabian Heavy, Arabian Medium, Arabian Light, and Iranian crude. Some characteristics of the oils are listed in Table 1. Dispersant was obtained from local supplier. Unfortunately, the supplier would not release any details and even brand name of the dispersant, due to commercial confidence.

\section{Preparation of oil dispersions}

To enhance dispersant effectiveness and to achieve greater uniformity of oil concentrations in both the

Table 1. Some typical characteristics of the test oils

\begin{tabular}{ccccc}
\hline Crude Oil ID & Arabian Heavy & Arabian Medium & Iranian & Arabian Light \\
\hline Gravity API at $15.6^{\circ} \mathrm{C}$ & 12.8 & 12.2 & 12.1 & 11.9 \\
Viscosity cSt at $15^{\circ} \mathrm{C}$ & 195 & 165 & 180 & $>360$ \\
Pour point & $18^{\circ} \mathrm{C}$ & $16^{\circ} \mathrm{C}$ & $15^{\circ} \mathrm{C}$ & $19^{\circ} \mathrm{C}$ \\
Flash point & $66^{\circ} \mathrm{C}$ & $60^{\circ} \mathrm{C}$ & $60^{\circ} \mathrm{C}$ & $78^{\circ} \mathrm{C}$ \\
\hline
\end{tabular}


water column and the oiled sediment layer, dispersant and oil were premixed. The dispersant-to-oil ratio (D:O) tested in water and sediment exposures was D:O $1: 10$. For intertidal sediments, a thin $(1$ to $5 \mathrm{~cm})$ layer of sediment was placed in an open-bottom (meshed) tray in a glass chamber of $500^{\mathrm{mm}} \times 250^{\mathrm{mm}} \times 400^{\mathrm{mm}}$. The sediment used in all cases has been described in earlier studies as a coarse beach sand (Harris and Wells, 1979).

In the chamber tests, a volume of about 30 liter of water was subjected to some form of turbulent mixing by pumping, and the effectiveness of the dispersant was measured at various dosages of dispersant to oil at a defined temperature. The preparation of oil dispersions in various mixing chambers was complicated by interactions between the three phases-oil, water, dispersant-and the chamber walls that were complex and difficult to reproduce.

\section{Sediments exposures}

The sediment, with relatively low water content $(15.7 \%)$ and high amounts of fine $(47 \%)$ and medium sand $(21 \%)$. It was tested together with commercially available artificial sands, the latter functioning as control or reference sediments. This procedure eliminates problems caused by pockets of low and high hydrocarbon concentrations on or beneath the surface created by oiling, as have occurred in many early experiments. Tidal flushing were simulated in each tank, with a gentle exchange of water through the sediment to prevent the formation of an anaerobic lower layer.

The relative oil/dispersant temperature was important to the performance of the chemicals. In McDonald's (1984) investigation, at a water temperature of $15^{\circ} \mathrm{C}$, when the temperature of the dispersant was decreased from 15 to $4^{\circ} \mathrm{C}$, the effectiveness of dispersant decreased from $56 \%$ to $40 \%$.

Water temperatures used here were 10, 20, 30 and $40^{\circ} \mathrm{C}$, and were maintained seperately through temperature controllers within $\pm 1^{\circ} \mathrm{C}$. The oil and dispersant were kept at the same temperature as the water.

\section{Adsorption characteristics of dispersed oil in marine sediment}

After the extent of sorption of dispersed oil to surface of sediment was determined, it was necessary to determine how tightly it was bond. Special cores were prepared that could be water flushed. The corer was hand-made from a 25-mm diamter stainless tube. Ten sediment samples of each type of treatment (oil alone, or oil plus dispersant at 1:10) were taken such that five of each would serve as initial values and the other five as final values after receiving a flushing with water, where water was freely drained through sediment layer under atmospheric pressure.

\section{Use soap water as alternative to chemical dispersant}

Based upon practical experiences of using laundry soap water for treating floating oil, 1-ml soap water with concentration of 0.5 and $1.0 \mathrm{~g} / \mathrm{ml}$ water was premixed with crude oil as an alternative to chemical dispersants. The soap tested was an ordinary laundry soap purchased from grocer.

\section{Quantitative analyses of oil components}

Sediment samples were extracted with $\mathrm{CCl}_{4}$ for oil content analysis. They were premixed with $\mathrm{CCl}_{4}$ and shacked vigorously for two minutes. To determine the effectiveness as affected by duration and temperature of extraction, sediment were repeatedly extracted at least four times.

Analyses of tested oil dispersions were routinely conducted using infrared spectroscopic technique (Yanagimoto OIL-103 Oil Analyzer), confirmed by gas chromatography (Hewlett Packards $830 \mathrm{~A}, \mathrm{FID}, 50^{\circ} \mathrm{C}$ at injection port, carrier gas: helium, $1 \mathrm{~mL} / \mathrm{min}$ ). Solid phase microextraction (SPME), a simpler and faster method was used for sample preparation. Infrared has proven to be popular and acceptable (Anderson et al., 1989). A major portion (96\% in average) of hydrocarbon oil were washed out from sediment by two $\mathrm{CCl}_{4}$ extractions. Same steps were followed for analyzing oil in sediment throughout this investigation.

\section{RESULTS AND DISCUSSION}

\section{Dispersion stability}

The stability (defined as: the ratio of the amount of dispersed oil after 30-min settling to the amount of originally dispersed oil) of the dispersion obtained was studied. This period was chosen after an initial test series where the settling time needed to achieve balance in the oil/water/dispersant mixture was determined according to Figure 1. The "dispersion stability" data gave a clue to what kind of dispersion is formed, and thus an indication of what might happen initially at sea. The results showed how important it was to screen the effectiveness of various dispersants to find a good formulation for extreme conditions.

Figure 2 presents the amount of dispersed oil (as a percentage of the amount originally dispersed) after 30 min of settling. From this figures, under $4^{\circ} \mathrm{C}$ dispersant formed much less stable dispersion than under $15^{\circ} \mathrm{C}$ and 


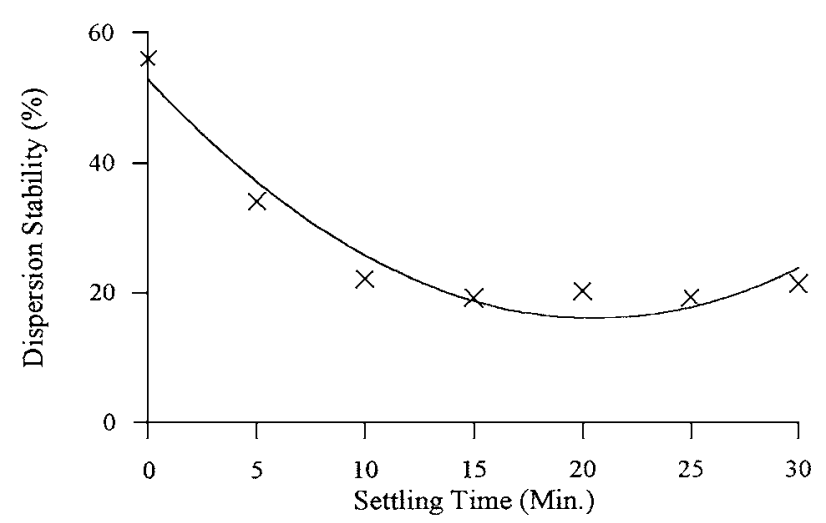

Fig. 1. The stability of the dispersion after a settling time of $30 \mathrm{~min}$.

$25^{\circ} \mathrm{C}$, whereas the difference between $15^{\circ} \mathrm{C}$ and $25^{\circ} \mathrm{C}$ was small in this respect.

\section{Adsorption characteristics of dispersed oil in sediments}

In this study dispersed oil in water was gradually drained through a bed of sediment to investigate the depth of penetration (Table 2). There was rather high variability among various water temperatures in the concentration of absorbed oil even at the same depth. Oil distribution in the top 0 to $3 \mathrm{~cm}$ sediment layer was, however, consistently related to the oil concentrations at deeper sediment layer. It was possible to obtain a better understanding of the distribution of dispersed oil by expressing the data in terms of percentage of the total oil in the core found at each of four depths ( 0 to 3,3 to 6 , 6 to 9 , and 9 to $12 \mathrm{~cm}$ ). The majority of the oil (approximately 85\%) was present in the top $3 \mathrm{~cm}$ of the cores.

To further understand the adsorption characteristics of the dispersd oil in sediments, control and treated sediments were flushed at atmospheric pressure for the same period. When only oil was mixed with sediment, the flushing caused about $31 \%$ of the absorbed oil to be washed away. The 1:10 dispersant to oil mixture pro-

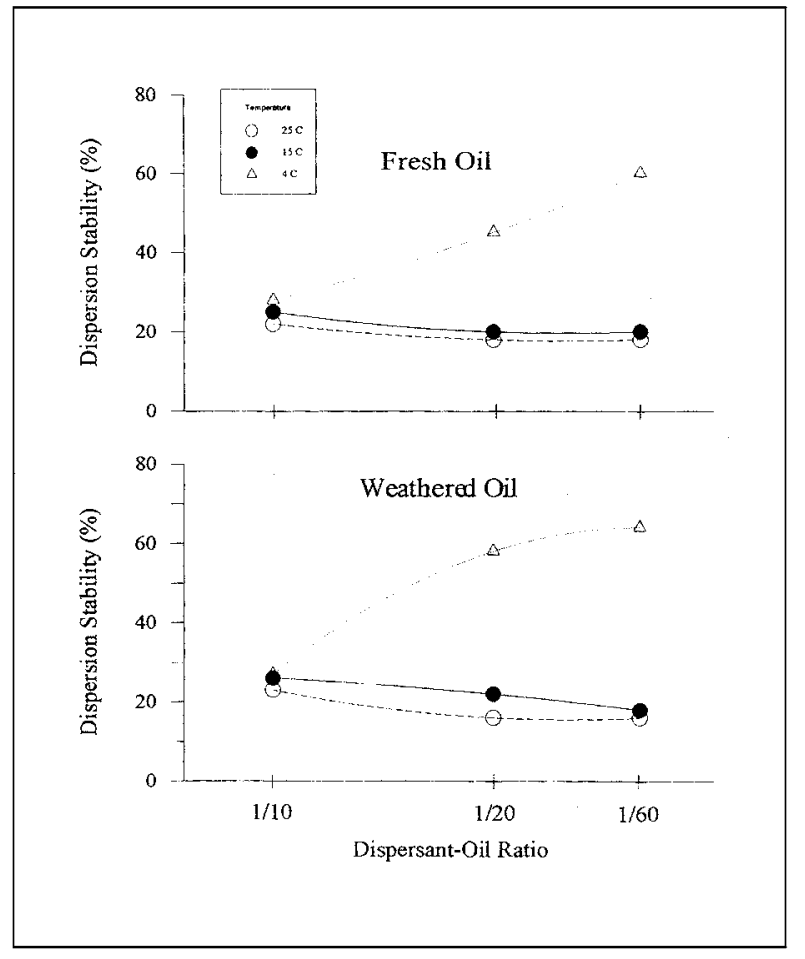

Fig. 2. The amount of dispersed oil after 30 min of settling.

duced a $40 \%$ loss during flushing.

\section{Temperature effect on oil adsorption to marine sediment}

Figure 3 illustrates the oil content in sediment, sampled from top layer and lower layer $(5 \mathrm{~cm}$ below surface) respectively at three temperatures $(10,30$, $40^{\circ} \mathrm{C}$ ), after three times of flushing. It was observed during experiments that water temperature played important role in affecting the dispersion behavior of dispersed oil in water. Oil dispersed evenly at higher temperature $\left(30\right.$ and $40^{\circ} \mathrm{C}$ ) while oil tended to flocculate at lower temperature $\left(10^{\circ} \mathrm{C}\right)$. From Figure 3 it can

Table 2. The depth of penetration of dispersed oil* in water

\begin{tabular}{|c|c|c|c|c|c|c|}
\hline \multirow[t]{2}{*}{$\begin{array}{l}\text { Core Depth } \\
\quad(\mathrm{cm})\end{array}$} & \multicolumn{6}{|c|}{ Temperature } \\
\hline & Conc., ml/L & $\%$ & Conc., ml/L & $\%$ & Conc., ml/L & $\%$ \\
\hline $0-3$ & 14846.1 & 88.0 & 13880.3 & 84.8 & 5725.1 & 86.1 \\
\hline $3-6$ & 1062.2 & 6.3 & 878.2 & 5.4 & 460.0 & 6.9 \\
\hline $6-9$ & 454.0 & 2.7 & 920.2 & 5.6 & 179.3 & 2.7 \\
\hline $9-12$ & 515.5 & 2.0 & 693.1 & 4.2 & 283.5 & 2.3 \\
\hline Total & 16877.8 & 100 & 16371.8 & 100 & 6647.9 & 100 \\
\hline
\end{tabular}

*Arabian Heavy Oil was used in this test. 


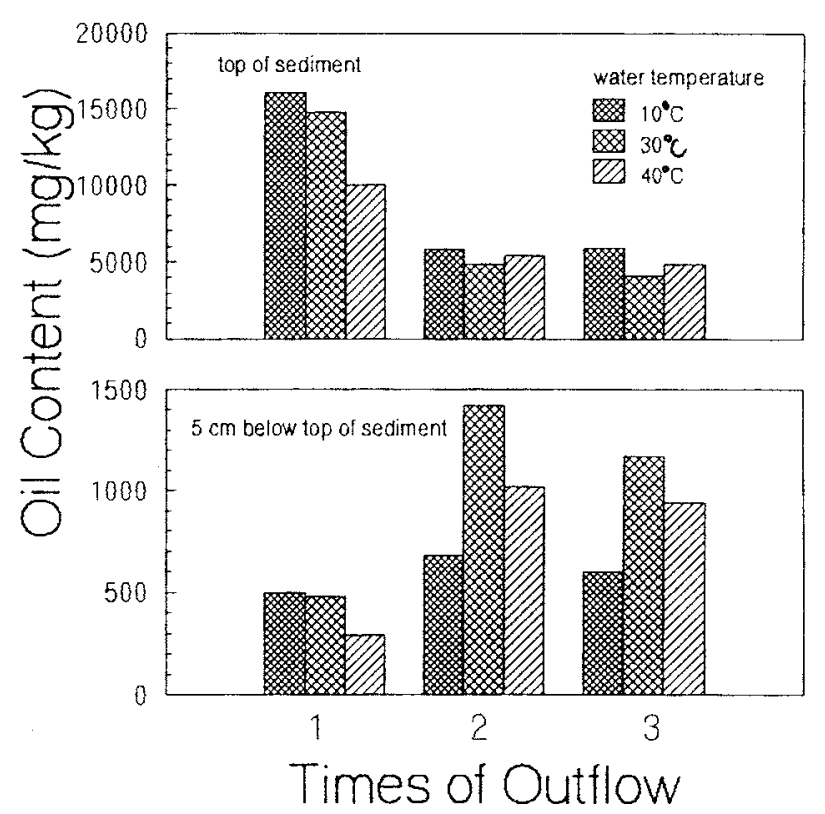

Fig. 3. The oil content in sediment, at three temperatures, after 3 time of flushing.

be seen that, after first water flushing, the retention of dispersed oil to the surface sediments decreased with higher temperature. However, after second and third flushing, the influence of temperature on the adsorption characteristics of dispersed oil to surface sediment is almost negligible. Dispersed oils were virtually remained in surface sediment after first flushing even when water temperature was increased from 10 to $30^{\circ} \mathrm{C}$. While oil retained in sediment decreased markedly after first flushing at water temperature of $40^{\circ} \mathrm{C}$. It implied that the retention capability of dispersed oil to marine sediment was diminishing with increase in water temperature, within certain temperature ranges.
Table 3. Adsorption of oil* on top sediment after flushing from beneath $(\mathrm{mg} / \mathrm{kg})$

\begin{tabular}{cccc}
\hline Test No. & After Flush & Difference & \% Loss of Oil \\
\hline 1:10 Dispersed Oil & & & \\
1 & 32097.6 & 18540.0 & 50 \\
2 & 23265.6 & 16779.1 & 43 \\
3 & 27316.8 & 17812.2 & 45 \\
4 & 28117.0 & 15994.0 & 42 \\
Oil Alone & & & \\
1 & 26683.2 & 9588.2 & 27 \\
2 & 24498.0 & 8763.2 & 30 \\
3 & 32100.0 & 9744.1 & 26 \\
4 & 32220.0 & 7977.2 & 32 \\
\hline
\end{tabular}

*Arabian Heavy Oil was used in the test.

\section{Sorption characteristics affected by times of flushing}

The loss of dispersed oil following first flushing was apparent in surface sediment (Figure 3). No more loss of dispersed oil from top layer was observed after second and third flushing. But in bottom sediments the dispersed oil increased with first flushing. It remained pretty much the same after second and third flushing. These results implied that in the field condition, most dispersed oil would be flushed from top sediment layer to the bottom by the tide right after oil spill incident, if dispersant was applied effectively.

To understand the adsorption characteristics of the dispersed oil in sediment, control and treated sediments were flushed through the tank at atmospheric pressure for the same period. Table 3 shows the retention of dispersed oil on surface sediment after flushing from beneath. When only oil was mixed with sediment, approximately $28 \%$ of the absorbed oil was washed out from top 2-cm sediment after flushing. The 1:10 dis-

Table 4. Sorption characteristics as affected by dosage of dispersant with: 1 / fixed dispersant/oil ratio (0.1), and 2/ fixed oil amount (varied dispersant/oil ratio).

\begin{tabular}{|c|c|c|c|}
\hline & \multicolumn{3}{|c|}{ Oil in sediments $(\mathrm{mg} / \mathrm{kg})$} \\
\hline & Surface & Bottom & Surface/Bottom \\
\hline \multicolumn{4}{|l|}{ dispersant/oil $=0.1$} \\
\hline $5 \mathrm{ml}$ oil, $0.5 \mathrm{ml}$ dispersant & 2262.4 & 168.0 & 13.5 \\
\hline $10 \mathrm{ml}$ oil, $1 \mathrm{ml}$ dispersant & 3814.8 & 268.8 & 14.2 \\
\hline $20 \mathrm{ml}$ oil, $2 \mathrm{ml}$ dispersant & 7996.8 & 514.4 & 15.6 \\
\hline $30 \mathrm{ml}$ oil, $3 \mathrm{ml}$ dispersant & 17920.0 & 1399.2 & 12.8 \\
\hline $50 \mathrm{ml}$ oil, $5 \mathrm{ml}$ dispersant & 53320.1 & 13392.2 & 4.0 \\
\hline \multicolumn{4}{|l|}{ Varied dispersant/oil ratio $(10 \mathrm{ml}$ oil $)$} \\
\hline 0 dispersant & 7860.0 & 130.4 & 60.3 \\
\hline $1 \mathrm{ml}$ dispersant & 7629.6 & 268.8 & 28.4 \\
\hline $6 \mathrm{ml}$ dispersant & 6308.1 & 250.4 & 25.2 \\
\hline
\end{tabular}

*Arabian Heavy Oil was used in the test. 
Table 5. Contents of four different crude oils in sediment after flushing

\begin{tabular}{ccc}
\hline Crude Oil & Surface Layer, $\mathrm{mg} / \mathrm{kg}$ & Bottom Layer, $\mathrm{mg} / \mathrm{kg}$ \\
\hline Arabian Light & 3000.0 & 111.4 \\
Arabian Heavy & 4152.2 & 160.2 \\
Arabian Middle & 4334.4 & 158.4 \\
Iran Light & 1287.2 & 98.2 \\
\hline
\end{tabular}

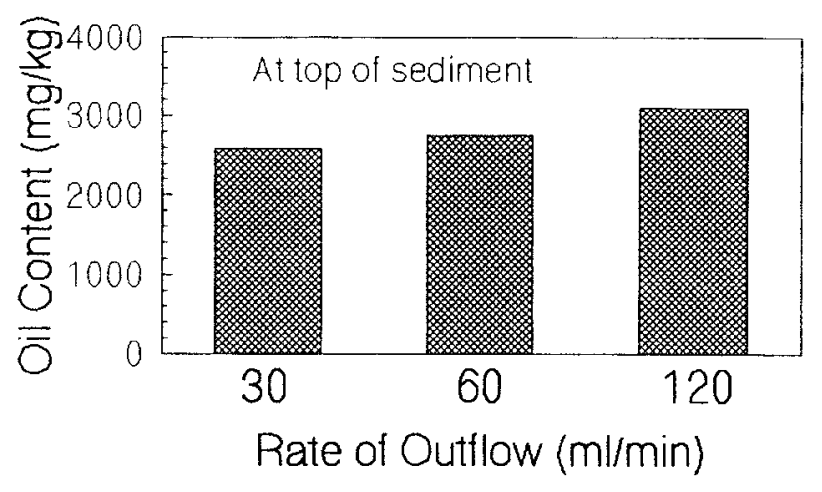

Fig. 4. The amounts of oil retained in surface sediment following various outflow rate of flushing.

persant to oil mixture produced a $45 \%$ loss during flushing.

\section{Effect of dispersant amount on oil retention in sediment}

Table 4 shows how the sorption characteristics of dispersed oil in marine sediments changed with various amounts of dispersant application, with constant dispersant/oil ratio of $1: 10$. Oils treated with dispersants are virtually retained in surface $2-\mathrm{cm}$ sediments following flushing in $60 \mathrm{ml} / \mathrm{min}$. The water temperature was maintained at $29 \pm 1{ }^{\circ} \mathrm{C}$ in this certain test. It was noticeable that with the same dispersant oil ratio, when the dosage of dispersant increased to $5 \mathrm{ml}$, quite significant amounts of oil was released from surface to the bottom sediment $(13392.2 \mathrm{mg} / \mathrm{kg})$. This implied that compared with the ratio of dispersant to oil, the amount of dispersant played a more important role in affecting oil characteristics in sediment.

In addition, Table 4 shows that with certain amount of oil and varied dispersant/oil ratio, oil in top sediments following flushing was not affected by the increase in dispersant application. In bottom sediment when dispersant application increased from 0 to $1 \mathrm{ml}$, oil in sediment following flushing was almost doubled. However, when dispersant application was further increased to $5 \mathrm{ml}$, no sign of oil accumulation in bottom sediments was observed after flushing. This could be explained by the loss of over dispersed oil which could

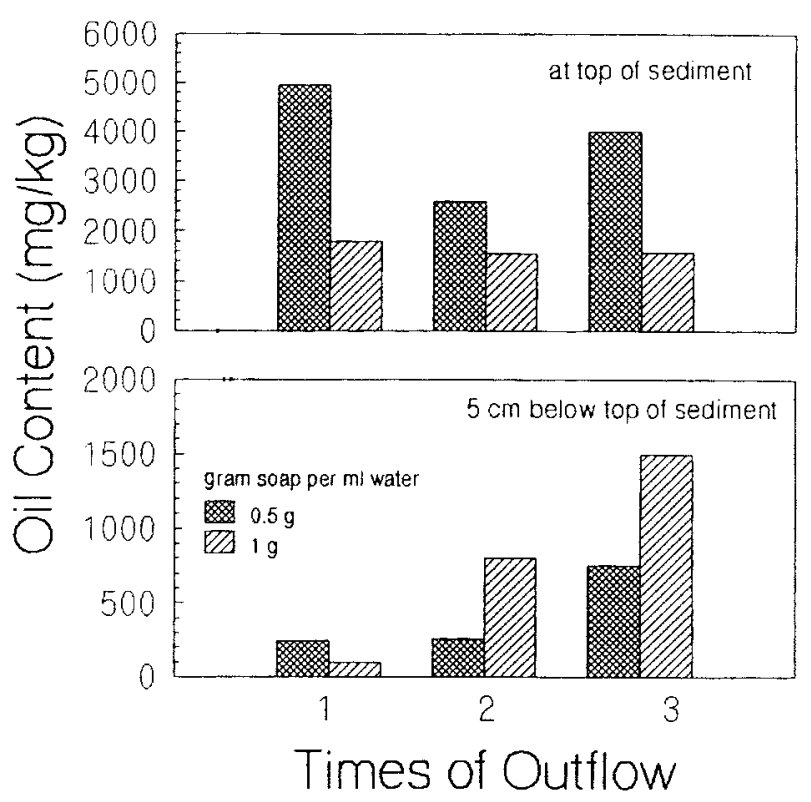

Fig. 5. Using soap water as alternative to chemical dispersant.

no longer be retained in sediment following flushing water. The ratios of oil in surface sediment to that in bottom sediment with fixed dispersant/oil ratio and with varied dispersant/oil ratio was compared on Table 4 (columm 4). In most cases, as the application dosage of dispersant increase, the ratios did not increase accordingly. Apparently, a higher ratio implied a lower tendency of dispersed oil to be washed out from surface sediment.

\section{Oil retention in sediment affected by water outflow rate}

Figure 4 shows that the dispersed oil did not pass through sediment layer easier with faster flushing as could be expected. When the outflow rate of flushing water doubled from $30 \mathrm{ml} / \mathrm{min}$ to $60 \mathrm{~mL} / \mathrm{min}$, the amounts of oil retained in surface sediment following flushing increased for about $6 \%$ (from 2590 to $2745 \mathrm{mg} / \mathrm{kg}$ ). When outflow rate was further increased from 60 to 120 $\mathrm{mL} / \mathrm{min}$, the increase of oil retention in sediments was even marked (approximately 13\%, from 2745 to 3102 $\mathrm{mg} / \mathrm{kg}$ ). The results illustrated that the dispersed oil may not be brought from top to deeper layer of marine 
sediments, by a faster flushing. On the contrary, due to a quicker loss of pore-water which dilute dispersed oil retained in marine sediment, the oil residues might tend to accumulate in surface layer of marine sediments, rather than moving deeper to the bottom.

\section{Use soap water as alternative to chemical dispersant}

In this certain test, sediment was repeatedly flushed at a flow rate of $30 \mathrm{~mL} / \mathrm{min}$. Temperature was maintained at $29 \pm 1{ }^{\circ} \mathrm{C}$. Soap water was tested as an alternative to chemical dispersant in this study.

Figure 5 shows the testing results. It was observed that the tested soap water acted effectively in dispersing floating oil. The performance of soap water in affecting the oil characteristics in marine sediment was rather similar to that of chemical dispersant used in this study.

\section{Characteristics of dispersed oil in sediment as affected by various crude oil}

Table 5 shows the contents of four different dispersed oils in sediment after flushing. Again oils were treated with dispersant, flushed with water through sediment layer at flow rate of $60 \mathrm{ml} / \mathrm{min}$.

Iranian light crude oil yielded the least oil residues in both top and bottom layer, among various oils. It was reasonable to explain that lighter crude were more difficult to retain in sediment and release to water more easily compared with heavier crudes. Similar trend was illustrated among three different Arabian crudes. In addition to the adsorption/desorption characteristic determined by oil and sediment property, the reaction between dispersant and various crude oil may be another factor need to be emphasized.

\section{CONCLUSIONS}

1. The influence of temperature on the adsorption characteristics of dispersed oil to marine sediment within 10 to $30^{\circ} \mathrm{C}$ is almost negligible in this study.

2 . With $10 \mathrm{~mL}$ of oil and varied dispersant/oil ratio $(0$, $0.1,0.6)$, oil in top sediments following flushing was not affected by the increase in dispersant application.

3. The application dosage of dispersant has no more influence on releasing oil to deeper sediment or water than the amount of oil applied.

4. When the outflow rate of flushing water doubled, the amounts of oil retained in surface sediment following flushing increased for about $6 \%$.

5 . The tested soap water acted effectively in dispersing floating oil, which was similar to that of the chemical dispersant used in this study.

\section{REFERENCES}

1. Harris, G.W. and P.G. Wells, 1979. “A laboratory study on the adhesion of crude oil to beach sand in the presence of a dispersant," Spill Technology Newsletter Sep-Oct. 1979, pp. 293-298.

2. Anderson, J.W., S.L. Kiesser, and J.W. Rapports. 1989. "Et Proces-verbaux des Reunions," Conseil Permanent Intenational pour l'Exploration de la Mer, Vol. 179. pp. 62-70.

3. Canevari, G.P.and G.P. Lindblom. 1996. "Toxicity testing with constant concentration of chemically dispersed oil," Marine Pollution Bulletin, 7(7):136-138.

4. Griffiths, R.P., T.M. McNamara, B.A. Caldwell, and R. Y. Morita. 1991. "The toxicity of oil spill dispersants to marine organisms," Marine Environmental Research, 5 (2):83-92.

5. Cox, J.H. 1981. "Field experiments on the effects of crude oil and dispersant on the common animals and plants of rocky sea shores," Marine Environmental Research, 8(4):215-239.

6. Schultz, T.P. 1981. "The fate and effects of dispersanttreated compared with untreated crude oil," In: Proceedings of the Artic Marine Oilspill Program 4th annual Technical Seminar, Environmental Protection Service, Ottawa, pp. 401-443.

7. Zitko, V. and B.D. Carson, 1969. "Effects of dispersant concentrations on marine organisms in the field," Marine Pollution Bulletin, 10(4):100-3.

8. Rowland, D.H. 1991. "An exposure scale for marine shores in Western Norway," Journal of the Marine Biological Association of the United Kingdom, pp. 975-996.

9. Karickhoff, S.M., D.S. Brown, and T.A. Scott. 1989. "Sorption of hydrophobic pollutants on natural sediments," Water Research. 13:241-248.

10. Pionke, G.B. and D.J. Chester, 1973. "The distribution of intertidal organisms along the coasts of the English Channel," Journal of the Marine Biological Association of the United Kingdom, 37(1):157-208.

11. Bailey, R.C. and D.W. White, 1970. "Methods of analysis for petroleum hydrocarbons," In: Effects of Petroleum on Arctic and Sub-arctic Marine Environments and Organism, Vol. 1, D.C. Malins, Ed. Academic Press, New York, NY, pp. 31-62.

12. McDonald, J.M. 1984. "Growth simulation following oil pollution," In: The Ecological Effects of Oil Pollution on Littoral Communities, E.B. Cowell, Ed., Institute of Petroleum, London, pp. 72-77. 


\title{
化學分散後之油在海洋底泥中的行爲
}

\author{
華 健
}

國立台灣海洋大學輪機工程系

摘 要

本文旨在描述在實驗室狀況下, 四種經化油劑 分散後之油在天然海洋底泥中所呈現出的特性。在 10 至 $30^{\circ} \mathrm{C}$ 之間, 温度對於分散後之油在底泥中吸附性質 無明顯影響。一定油量在不同化油劑與油之比例下, 底泥所吸附的油並不受增加化油劑量所影響。数於分 散後之油從表層底泥釋出至底層或水中, 所添加油量 的影響略超過所添加化油劑量的影響。當水的排出流 率加倍時, 滞留在表層底泥的油增加約 $6 \%$ 。觀察發 現肥息水能有效分散浮油, 且分散效果接近本研究所 採用分散劑者。 